\title{
AN INVESTIGATION ON HOSPITAL SOLID WASTE MANAGEMENT IN IRAN
}

\author{
FARZADKIA M. ${ }^{1}$ \\ EMAMJOMEH M.M. ${ }^{2}$ \\ GOLBAZ S. ${ }^{3, *}$ \\ SAJADI H.S. ${ }^{4}$
}

\author{
${ }^{1}$ Department of Environmental Health Engineering \\ Faculty of Health, Iran university of Medical Sciences, Tehran, Iran \\ ${ }^{2}$ Social Determinants of Health Research Center \\ Qazvin University of Medical Sciences, Qazvin, Iran \\ ${ }^{3}$ Department of Environmental Health Engineering, Faculty of Health \\ Tehran university of Medical Sciences, Tehran, Iran \\ ${ }^{4}$ Health Management and Economics Research Center \\ Isfahan University of Medical Sciences, Isfahan, Iran
}

Received: $17 / 09 / 2015$

Accepted: 30/10/2015

Available online: 04/11/2015 *to whom all correspondence should be addressed: e-mail: golbazs@gmail.com

\section{ABSTRACT}

The integrated hospital solid waste management emphasizes the need to conduct a survey based on a standardized method that equally be analyzed at national level. This study aimed to test the usability of a national tool to do integration data analysis of hospital waste management status. Then, a typical study was conducted in Karaj hospitals. Also, critical analysis of hospital's solid waste management aspects was done, and shortcomings in the aspects were identified. The pilot study results showed that the daily per capita waste generations were reported to be $4.2 \pm 0.49 \mathrm{~kg} /$ available bed, $5.8 \pm 0.63 \mathrm{~kg} / \mathrm{occupied}$ bed, and $10.3 \pm 0.9 \mathrm{~kg} /$ inpatient. The names of the hospitals were omitted when they were named from $\mathrm{H}_{1}$ to $\mathrm{H}_{8}$. So the highest and lowest daily waste generation rate were $5.5 \pm 0.35$ and $2.6 \pm 0.78 \mathrm{~kg} /$ available bed in $\mathrm{H}_{7}$ and $\mathrm{H}_{3}$ hospitals, respectively. In this study, total infectious wastes per capita were reported to be $2.3 \pm 0.39$ $\mathrm{kg} /$ available bed/day, $3 \pm 0.5 \mathrm{~kg} / \mathrm{occupied}$ bed/day and $5.2 \pm 0.84 \mathrm{~kg} /$ inpatient/day. Furthermore, the averages per capita of total general waste were $2 \pm 0.4 \mathrm{~kg} /$ available bed/day, $2.8 \pm 0.51 \mathrm{~kg} /$ occupied bed/day and $5.1 \pm 0.8 \mathrm{~kg} /$ inpatient/day. Analysis of the Karaj hospital waste management status showed statue of hospital waste management in $88 \%$ of hospitals were ranked moderate when others were achieved to be poor by $12 \%$. The hospital waste management had been evaluated poor in term of collection, transportation and manpower aspects, moderate in the separation and temporary storage aspects and good in the disposal aspect. It was also found that the MOHME tool is appropriate tool to investigate the status of waste management in hospitals.

Keywords: Hazardous waste, Hospital waste, Waste management

\section{Introduction}

One of the major sources of waste generation are produced by various spectrum of health care providers especially hospitals (Sabour et al., 2007, Wong et al., 1994). Due to having pathogenic microbial factors, hazardous chemical and radioactive substances as well as sharp components, these materials are considered hazardous waste (Adegboye et al., 1994, Prüss et al., 1999). More than ever the risk to the natural environment caused by these materials requires a strict and rigorous supervision in the process of collection, transportation and disposal. Obviously, any negligence in the management of these wastes 
may have direct or indirect adverse effect on the environment and human health (Amooei, 2003, Tudor et al., 2005, Da Silva et al., 2005, Akter, 2000).

According to a survey conducted in twenty-two developing countries, 18 to $64 \%$ of hospital waste is not disposed properly and leads to the pollution of water resources and the environment (Allegranzi and Pittet, 2007). Thus, the need for better management of hospital waste made developed countries insist on passing legislation that would be instructions for the collection, transportation and maintenance of medical waste. Also, these countries have continued to try to find new technologies for proper treatment and disposal of medical waste. However, research suggests that in the developing countries adequate attention is not paid to the issue of medical waste management and its simultaneous disposal with domestic solid waste is a serious threat to public health and the environment.

Reviewing previous studies in Iran shows that despite the waste laws and its executive regulations, hospital waste management does not take place properly due to inadequate monitoring. Lack of separation of semi-domestic and hazardous waste (Askarian and Vakili, 2005, Farzadkia and Moradi, 2009, Ebadifard et al., 2005, Askarian et al., 2010), lack of necessary facilities for treatment of infectious waste (Mohseni et al., 2001, Farzadkia et al., 2013), inadequate training of staff and lack of foresight personal protective equipment (Raigan Shirazi et al., 2008) are the main problems in the hospital waste management. Improvement of hospital waste management requires complete knowledge and understanding of the quality and quantity of producing waste, storage, collection and transportation of these materials in addition to the methods of their treatment and disposal. Previous studies in the cities of Yasuj (Raigan Shirazi et al., 2008), Qom (Jonidi et al., 2010), Mazandaran (Mohseni et al., 2001), some hospitals of Tehran (Yaghoubifar, 1998), showed that the medical waste management is important subject in Iran.

A medical (Health Care) waste means any infectious and harmful wastes generated by hospitals, health and treatment facilities, medical laboratories and other similar facilities. Other harmless hospital wastes are not included. Due to Iranian regulation, Medical wastes as well as some parts of ordinary, industrial and agricultural wastes which require special type of management are considered as special wastes. Mixing of medical wastes with other wastes and their discharge and dispersion in the environment or sale, use, and recycling this kind of waste is prohibited. Achieving suitable separation of treatment wastes at all the health center in Tehran (capital of Iran), reducing $80 \%$ of the medical waste produced disposed as hazardous waste, determination of economic and suitable methods for the environment to dispose the hazardous wastes in Tehran as well as presentation suitable method of separation hazardous wastes and disposing the same shall be deemed as the objectives of the organization in the field of medical wastes management (Tmpird et al., 2008). Currently in Iran, due to policies of Health Ministry, the hospitals (and other major producers of medical waste) have selected on-site treating method as the preferred treatment. Because, according to Act 64 in Iran's Medical Waste Management Regulations, all waste producers in middle-sized and large cites are responsible for treating hazardous-infectious waste and converting it into general waste in on-site facilities(Taghipour et al., 2014)

Systematic planning to improve hospital waste management in each country requires implementation of a comprehensive plan of the current status of waste. Due to the high cost of studies on such programs, a large-scale regional plan was implemented in different parts of the country and its results, in addition to the regional effectiveness were integrated into a national program. During the last three decades, the researchers have carried out several studies on the status of hospital waste management in different cities of Iran (Koushiar et al., 2006, Arab et al., 2008). A literature review indicated that these studies were extremely expensive and high costs are imposed on the health system; therefore, use of their results is not yet possible in the form of a national program. One reason for the low efficacy results of these studies includes the lack of a standardized, applicable and comprehensive method for assessing the existing status of generation, separation, collection, transportation, temporary storage, disposal and manpower. So, the comparison of the results of these studies was approximately impossible, due to heterogeneous results. In other words, these studies used various methods to analysis the status of waste management in hospital. Thus, using the results of the studies to improve hospital waste management situation has been 
difficult and nearly impossible. Therefore, complete knowledge and understanding of the hospital waste management statue cannot be obtained, which is the basis for decision making to improve the current situation. The integrated hospital solid waste management emphasizes the need to conduct a survey based on a standardized applicable and comprehensive method at national level. This study aimed to test the usability of a national tool to do integration data analysis of hospital waste management status. Then, a typical study was conducted in Karaj hospitals. Also, a critical analysis of hospital's solid waste management aspects was performed in keeping with the provisions made rules, and shortcomings in the aspects were identified. With a view to overcoming these shortcomings, indicative strategies and guidelines for action plan preparation were formulated. Solid waste disposal and waste management systems are not satisfactory in many hospitals in Iran (Karamous et al., 2007). Little information is available regarding the generation and disposal of medical waste in Iran, and is needed to have better management for the hospital wastes (Askarian et al., 2004a, Arab et al., 2008). Therefore, the hospitals have found a convenient way to manage their waste according to performance standards. In order to proper programming for the implementation of these standards, this research was carried out by analyzing the current state of medical waste management.

\section{Material and Methods}

This study was designed in two stages. The first stage related to select an applicable method to evaluate the data of status of hospital waste management. The second stage involved using this method for analysis of the data of Karaj hospital waste management status. The methodology for this study is presented in Fig. 1.

After doing a literature review, to evaluate the current status of waste management in hospitals, the questionnaire prepared by The Ministry of Health and Medical Education (MOHME) in Iran is selected. It seems that the questionnaire developed and validated by The Ministry of Health and Medical Education in Iran is an appropriate tool to investigate the status of waste management in the hospital. Because of all the criteria contained in the questionnaire were based on the World Health Organization (WHO) and United States Environmental Protection Agency (EPA) guidelines. This questionnaire covered all important issues to examine the different aspects of solid waste management. The questionnaire had two parts. The first part included general hospital information (16 questions): hospital name and type; the number of staff, departments and beds; and the latest accreditation degree and etc. The second part consisted questions to evaluate the hospital waste management process in 6 areas including separation (12 questions), collection (5 questions), transportation (4 questions), temporary storage (6 questions), disposal (4 questions) and manpower (7 questions) aspects. To reach homogeneous data, two alternatives (Yes and No) were designed. In order to analyze data, code 1 was assigned to answers which complied with the law (positive) and code 0 was assigned to those which did not comply with the law (negative). Then, frequency of positive and negative responses were calculated for each part of the hospital waste management and were converted in to $0-100$ to be classified. Six dimensions of health status such: medical mission hospital, environmental health hospital, hospital wastes, hygiene of water and wastewater in hospital, occupational health, and patient's hygiene and infection control was considered. Highest standard in each of the six dimensions of environmental health status was measured equal to the sum of the maximum score for each of the questions and the lowest standard. So, ranking of the hospital waste management status was done in three categories including poor $(0-60)$, moderate $(60-80)$, and good (80 - 100) (Jonidi Jafari et al., 2013).

In the second stage, the typical study was carried out in 2014 in hospitals across Karaj. All hospitals of Karaj had been selected as statistical population of this study $(n=8)$ by census, including four teaching hospitals, three private hospitals and one social security hospital. The mentioned questionnaire was completed by looking at the hospitals.

Due to the fact that the waste was not weighed at the studied hospitals, separating and weighing operations were done with coordination of the hospital's local director and introduction of the required service personnel. In this section of the study, in addition to training each employee for personal hygiene 
standards, an attempt was made to use individuals who had been previously vaccinated against hepatitis B. Sampling and weighing of waste was carried out for four months (one week per month). Four months including the months of each season in year. The study was conducted in 2013 when it was done in one year.

The weighing procedure was as follows:

- Weighing of empty bin $\left(W_{b}\right)$ using a weighing balance. Tied bags containing waste in temporary storage place was weighed using digital balance.

- Filling of the bin with sample waste while shaking the bin constantly to avoid undue void spaces. Finally, the difference between full and empty container was found in any part of hospital waste.

- Weighing of the bin filled with sample waste $\left(\mathrm{W}_{T}\right)$ using a weighing balance

- Determination of the average number of inpatients to generate the waste in each hospital at the time of measurements $(\mathrm{t})$

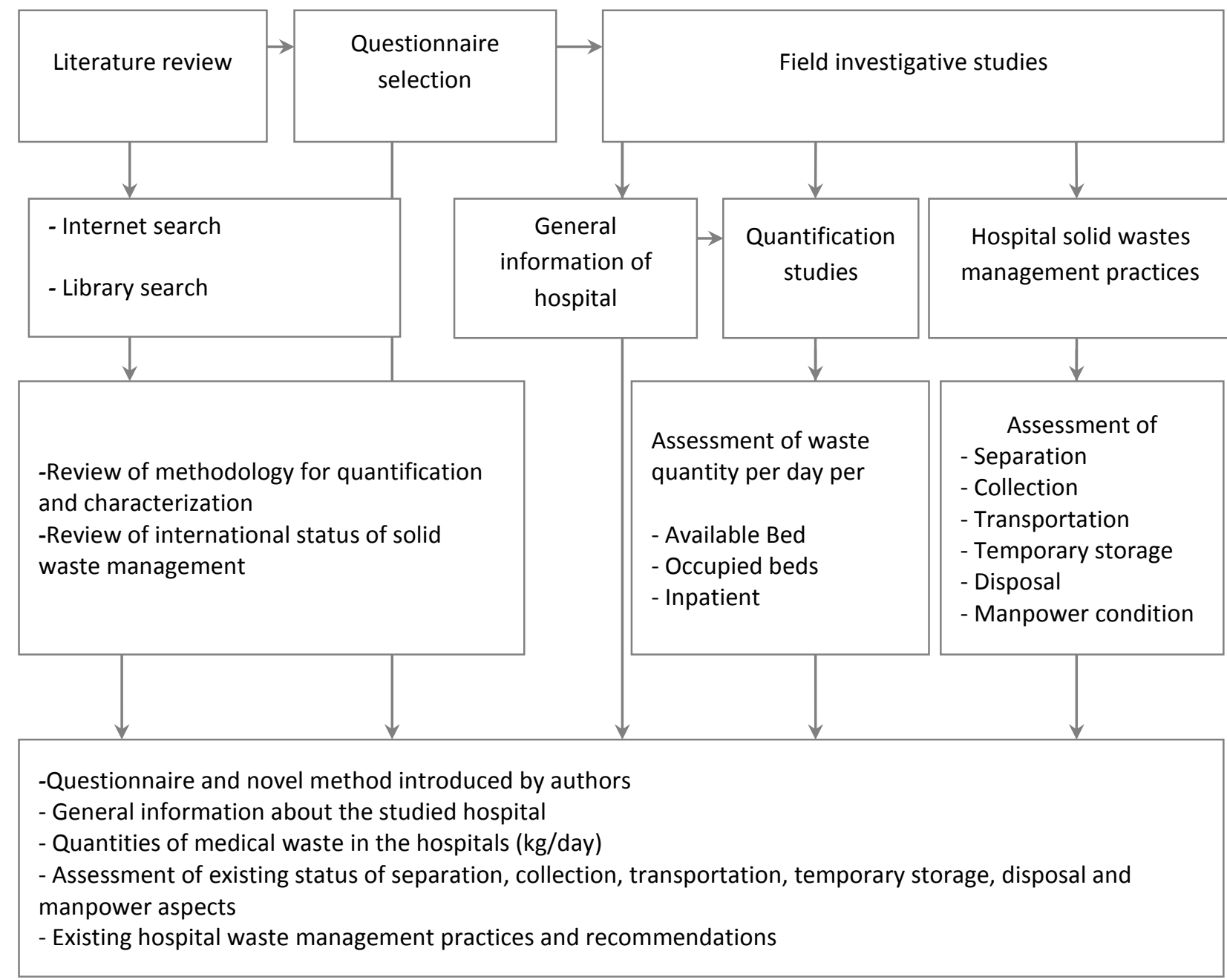

Figure 1. Summarized research methodology

Patients following a six-hour stay in the hospital, defined as outpatients. The presence of more than six hours at the hospital, the patient is hospitalized when were called Inpatient. The waste generated rates $\left(W_{G}\right)$ per occupied bed, available bed, and inpatient per day was calculated by the following equations:

$\mathrm{W}_{\mathrm{G}}=\frac{\sum\left(\mathrm{W}_{\mathrm{T}}-\mathrm{W}_{\mathrm{b}}\right)}{\text { inpatient }}=(\mathrm{kg} /$ ipatient $/$ day $)$ 


$$
\mathrm{W}_{\mathrm{G}}=\frac{\sum\left(\mathrm{W}_{\mathrm{T}}-\mathrm{W}_{\mathrm{b}}\right)}{\text { Available Bed or Occupied Bed }}=(\mathrm{kg} / \mathrm{bed} / \text { day })
$$

Where in patient is a hospital patient who occupies a bed for at least one night in the course of treatment, examination, or observation; available bed is the number of beds available to provide overnight accommodation for patients; and number of beds occupied obtained due to inpatient bed occupancy rate.

$$
\text { Occupancy rate }=\frac{\text { Total number of inpatient days for a given period } \times 100}{\text { Available beds } \times \text { Number of days in the period }}=\%
$$

Data had been analyzed using Excel and SPSS software. After obtaining university ethics committee license and relevant introduction letters, this study was conducted. In addition to the bases of principle, and confidentiality, in regards to the collected and use of the information obtained from each hospital, the names of the hospitals were omitted and instead were referred to as $\mathrm{H}_{1}$ to $\mathrm{H}_{8}$.

The Department of Health has developed national guidelines on the management of hospital waste. Color is used to differentiate containers for storing various types of hospital waste at the generation point (Table 1). Infectious waste should be stored in a yellow marked strong leak proof bag or container. Chemical and pharmaceutical waste is should be stored in a brown marked plastic bag or container. Black marked plastic bags in containers are to be used for storing general waste. Sharp objects or equipment are to be stored in a yellow marked puncture proof container with lids.

Sharp, infectious, pathological, and chemical wastes were all collected in yellow plastic bags. In some wards, the site survey showed that these wastes were also mixed with general waste.

\begin{tabular}{|c|c|c|c|}
\hline Types of waste & Container & $\begin{array}{l}\text { Color used by } \\
\text { hospitals }\end{array}$ & Recommended colors \\
\hline General & $\begin{array}{l}\text { Plastic bag in blue bin } \\
\text { container }\end{array}$ & Black plastic bag & Black plastic bag \\
\hline $\begin{array}{l}\text { Chemicals, and } \\
\text { pharmaceutical }\end{array}$ & $\begin{array}{l}\text { Plastic bag in yellow/ blue bin } \\
\text { container }\end{array}$ & Yellow plastic bag & $\begin{array}{c}\text { Brown plastic bags/ } \\
\text { container }\end{array}$ \\
\hline $\begin{array}{l}\text { Clinical, infectious, } \\
\text { pathological }\end{array}$ & $\begin{array}{l}\text { Plastic bag in yellow/ blue bin } \\
\text { container }\end{array}$ & Yellow plastic bag & $\begin{array}{l}\text { Yellow plastic bags/ } \\
\text { container }\end{array}$ \\
\hline Sharps & $\begin{array}{c}\text { Yellow bin in yellow bin } \\
\text { container }\end{array}$ & Yellow bin & Yellow bin \\
\hline
\end{tabular}

Table 1 .Showing the types of containers used to collect different types of hospital waste

\section{Results and discussion}

In this section, findings are presented in three parts: general information, quantity, and management of hospital solid waste.

\subsection{General information about the studied hospital}

General information of the studied hospital is given in Table 2.

Table 2. General information for the studied hospital

\begin{tabular}{cccccc}
\hline Hospitals & $\begin{array}{r}\text { Number of } \\
\text { approved beds }\end{array}$ & $\begin{array}{c}\text { Number of } \\
\text { operating beds }\end{array}$ & $\begin{array}{c}\text { Number of } \\
\text { wards }\end{array}$ & $\begin{array}{c}\text { Establish year of } \\
\text { hospital }\end{array}$ & $\begin{array}{c}\text { Number of } \\
\text { personnel }\end{array}$ \\
\hline $\mathrm{H}_{1}$ & 199 & 117 & 9 & 1982 & 406 \\
$\mathrm{H}_{2}$ & 200 & 115 & 15 & 1991 & 543 \\
$\mathrm{H}_{3}$ & 225 & 181 & 10 & 1979 & 474 \\
$\mathrm{H}_{4}$ & 350 & 314 & 15 & 2000 & 500 \\
$\mathrm{H}_{5}$ & 316 & 133 & 17 & 2001 & 825 \\
$\mathrm{H}_{6}$ & 190 & 70 & 7 & 1951 & 492 \\
$\mathrm{H}_{7}$ & 70 & 178 & 12 & 1971 & 320 \\
$\mathrm{H}_{8}$ & 190 & & & 1963 & 508 \\
\hline
\end{tabular}


The average number of beds and employees was 174 and 508, respectively. All hospital centers have an environmental health specialist with bachelor degree. Moreover, all environmental health specialists were present in the health and hospital infection control committee, and passed courses relating to solid waste.

\subsection{Generation of medical waste in Karaj}

As can be seen in Fig 2, the medical waste generation rates were reported to be $4.2 \pm 0.49 \mathrm{~kg} /$ available bed, $5.8 \pm 0.63 \mathrm{~kg} /$ occupied bed, and $10.3 \pm 0.9 \mathrm{~kg} /$ inpatient. The results also showed that these generation rates were different from one hospital to the other hospital. So the highest and lowest daily waste generation rate were $5.5 \pm 0.35$ and $2.6 \pm 0.78 \mathrm{~kg} /$ available bed in $\mathrm{H}_{7}$ and $\mathrm{H}_{3}$ hospitals, respectively. Results of studies in different provinces, apart from confirming this issue, showed that the rate of waste generation per bed for the provinces of Semnan 3.6, Esfehan 3.14, Fars 3.30, Markazi 3.24, Yazd 3.45, Ardebil 3.53, Boushehr 3.8, Zanjan 2.92, Azarbayjan Gharbi 3.20, Guilan 3.16, Qom 2.87 (Sabour et al., 2007), Kashan 3.44 (Mostafaei et al., 2004), cities of Tehran 2.7 (Hassan et al., 2008), Babol 2.01 (Amooei, 2003), Shiraz 4.45 (Askarian et al., 2004b), Mashhad 1.67 (Sadeghi, 2001), Tabriz 3.48 (Taghipour and Mosaferi, 2009) and Yasoj $5.5 \mathrm{~kg} /$ day (Raigan Shirazi et al., 2008).

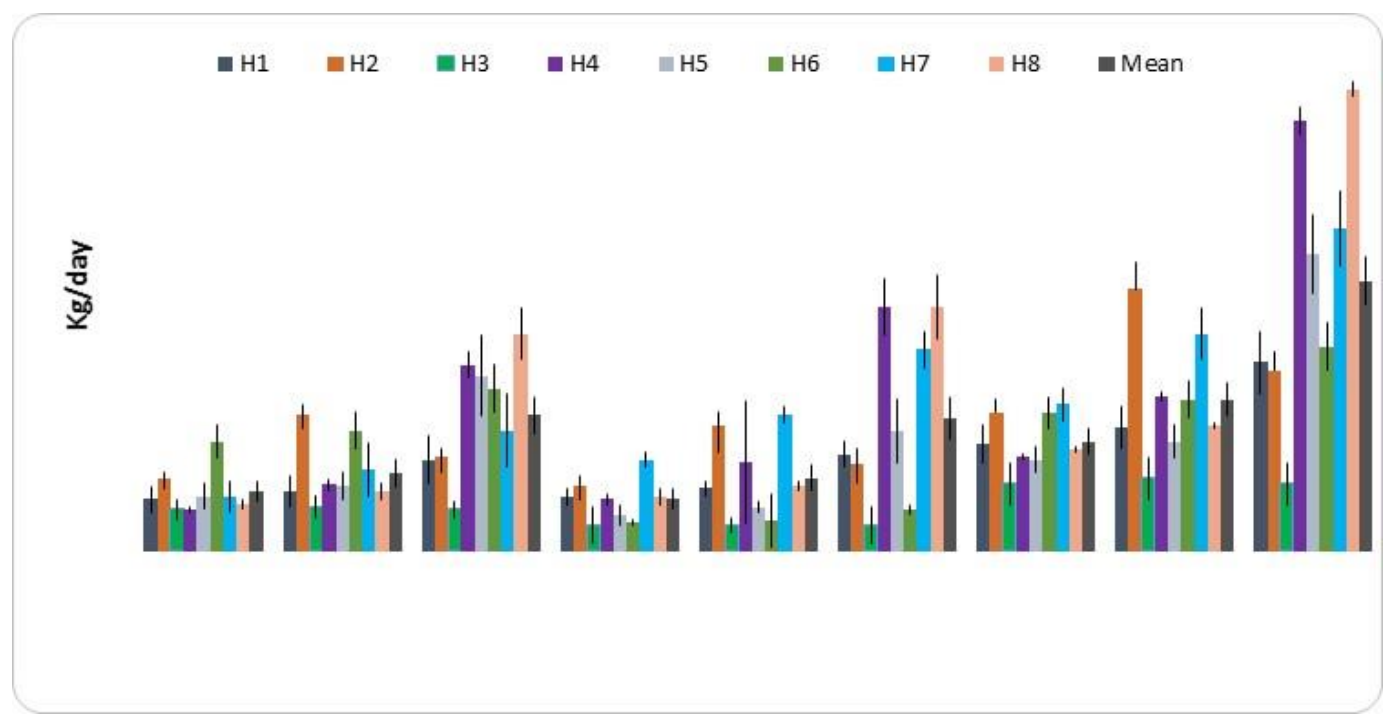

Figure 2. Quantities of medical waste generation rate in the hospitals of Karaj

In this study, total infectious wastes per capita were reported to be $2.3 \pm 0.39 \mathrm{~kg} /$ available bed/day, $3 \pm 0.5$ $\mathrm{kg} /$ occupied bed/day and $5.2 \pm 0.84 \mathrm{~kg} /$ inpatient/day. Furthermore, the averages per capita of total general waste were $2 \pm 0.4 \mathrm{~kg}$ per available bed per day, $2.8 \pm 0.51 \mathrm{~kg}$ per occupied bed per day and $5.1 \pm 0.8$ kg per inpatient per day. Per capita of infectious waste in the studies conducted in Yasouj and Babol were 1.5 and $0.67 \mathrm{~kg} / \mathrm{bed} /$ day, respectively (Amooei, 2003, Raigan Shirazi et al., 2008). In other studies, Silva et al, (2005) reported an average rate of biological-infectious waste production of $0.57 \mathrm{~kg} / \mathrm{bed} / \mathrm{day}$. The high generation rate of infectious waste compared to non-infectious waste in the studied hospitals to other studies can be due to the lack of a systematic plan for the operation of waste separation. Thus, it is suggested that those who are responsible for the hospital waste management should place operation of hospital waste separation at the origin of their agenda. Existing experience attributed to waste management in the developed countries, indicate that these practices can reduce infectious waste to a normal amount in hospitals (15 to $20 \%$ ) (Raigan Shirazi et al., 2008).

Authoritative references reported that waste production rate in developing countries was $1-2 \mathrm{~kg} / \mathrm{bed} / \mathrm{day}$ (Raigan Shirazi et al., 2008, Parandeh and Khanjani, 2012). Also, some of the external sources have reported waste production rate as the following: 
A study conducted in Dhaka reported the per capita was $1.2 \mathrm{~kg} / \mathrm{bed} /$ day (Patwary et al., 2009). Studies of waste generation rates in the European countries, hospitals indicated that this index was $3.6 \mathrm{~kg} / \mathrm{bed} / \mathrm{day}$ in Germany, $1.7 \mathrm{~kg} / \mathrm{bed} /$ day in the Netherlands and $3.3 \mathrm{~kg} / \mathrm{bed} /$ day in England(Majlesi et al., 2007). A study conducted in Brazil estimated average of hospital waste as $3.5 \mathrm{~kg} / \mathrm{bed} /$ day (Da Silva et al., 2005). According to the released results, the above mentioned value was 2.41 to $3.26 \mathrm{~kg} / \mathrm{bed} / \mathrm{day}$ in Taiwan (Cheng et al., 2010), $1.3 \mathrm{~kg} / \mathrm{bed} /$ day in Libya (Sawalem et al., 2009), 1.5-3.9 kg/bed/day in Canada, 2.4 $\mathrm{kg} / \mathrm{bed} /$ day in Tanzania (Mato and Kassenga, 1997), 0.5-2 kg/bed/day in India (Prüss et al., 1999), 1 $\mathrm{kg} / \mathrm{bed} /$ day in Thailand (Kerdsuwan, 2000), $1.2 \mathrm{~kg} / \mathrm{bed} /$ day in Bangladesh (Patwary et al, 2009), and 3.3 $\mathrm{kg} / \mathrm{bed} /$ day in southern Brazil (Da Silva et al., 2005). Other comparisons of the generation rate have also been summarized in Greece, Cameroon, and Turkey. In Greece, The average total hazardous medical waste unit generation rates varied from $0.012 \mathrm{~kg} / \mathrm{bed} / \mathrm{day}$, for the public psychiatric hospitals, to up to $0.72 \mathrm{~kg} / \mathrm{bed} / \mathrm{day}$, for the public university hospitals (Komilis et al., 2012). Total quantity of wastes generated in the Health Care Facility in Cameroon is not reported based on number of beds. The waste stream is complex and heterogeneous with an average waste generation rate estimated at $44.9 \mathrm{~kg} / \mathrm{day}$ (Mangaa et al., 2011). In Turkey, It was found that the estimated quantity of medical waste from the hospitals is about 22 tons/day and the average generation rate is $0.63 \mathrm{~kg} / \mathrm{bed} /$ day (Birpinar et al., 2009).

As mentioned above, the values show that waste generation rates per bed varied between different countries, different cities of a country and even the different hospitals of a city. In the previous conducted studies in Iranian hospitals such as Fars (Askarian et al., 2004a) and Tabriz (Taghipour and Mosaferi, 2009) as well as hospitals in Brazil (Da Silva et al., 2005) and Jordan (Bdour et al., 2007), similar differences were observed. The causes of these differences can be attributed to the following; condition and capacity of a hospital, the nature and quality of medical services, standard of equipment, hospital location, variety of sections of the hospital (for example surgery, general and etc.), hospital observance of health standards, cultural, economic and social context, the number of patients and students (for training), laboratory areas, use of disposable materials, number of registered surgeons, type of medical equipment, use of disposable products in the hospital, attention to different aspects of hospital waste management (especially separation, recycling, reuse and purification of infectious waste and different levels of staff training in regards to waste management) (Da Silva et al., 2005, Taghipour and Mosaferi, 2009, Nemathaga et al., 2008, Askarian et al., 2004a). In this study, normal regression analysis showed that the number of inpatient and ward are highly effective in hospital solid waste generation ( $p_{\text {value }}<0.005$ ).

\subsection{Hospital waste management}

The status of hospital waste segregation at source is shown in Fig. 3a. The most frequent of medical waste separation status was moderate (62\%). In this part, the highest percentage of negative response (100\%) was related to the strict observance of standards of waste separations at source. The results revealed that one of the reasons for incomplete waste separation in these hospitals was the lack of initial training of nurses and new personnel, while service sectors personnel were constantly changed or replaced. Thus indicating that it is necessary to repeat trainings constantly similar conditions were reported by Sawalem et al., (2009). Accordingly, it is suggested that trained and experienced individuals should be used when dealing with the management of solid waste. Furthermore, if possible, lower turnover and job displacement should take place. The other cause of inattention to the strict observance of standards of waste separation in the origin is related to the condition of a severally ill patient. In such cases, a need for giving more services leads to inattention of health personnel to waste separation. The primary responsibility of hospital waste separation is placed on its producers (such as doctors, nurses, and paramedics). As long as health care staffs are not aware of this issue and do not execute it, it will not be modified under any circumstances (Mousavi et al., 2005). Unfortunately, at present this responsibility is mainly placed on the waste collection sector. Obviously only the separation of mixed wastes will not solve the problem, but also strongly increases the unhealthy condition. Also, recycling of any segregated wastes is not currently being practiced on-site.

Moreover, results indicate that hospitals in collection aspect were poor $62 \%$, and moderate $38 \%$ (Fig. 3b). In this part, the oversight in washing and disinfecting waste bins after each use, and the lack of labeling 
waste bags were of the main shortcomings observed. Lack of labeling of waste bags leads to the failure to identify waste inside the bags during temporary holding and eliminates the ability to track fluctuations in waste production in hospital wards. Thus, any sudden increase or decrease in the waste generation cannot be tracked and removed in different sections.

Looking at the hospitals revealed that in $85 \%$ of them, designated people were not assigned to collect and transport solid waste. While it is very important to apply specialized waste-workers in collecting solid waste, it is suggested to use an adequate number of trained people in collecting and transporting hospital waste. In the study of the hospital solid waste management in five hospitals in the city of Tehran the presentation of improvement approaches, Farzadkia et al., (2011) concluded that health level of the collecting system in $20 \%$ of centers was poor and in $40 \%$ was good. These results are close to our findings. In some studies, the main reasons for the poor condition of hospital waste collection are items such as: manual waste collection and the inappropriate condition of solid waste collection frequency (Coker et al., 2009, Al-Khatib and Sato, 2009).

Site surveys at the hospitals showed that most wards did not have a temporary storage room for putting containers that get full during the day or at night. But all hospitals have a temporary storage room outside of the hospital building. So, the collected wastes from the wards were directly transferred to temporary storage outside of the hospital building. In this stage, findings showed that $100 \%$ of hospitals were in poor condition (Fig. 3c). Looking at hospitals revealed that most of the waste management problems are related to workers performance. For example, while collecting and transporting waste workers do not take into consideration the color of the containers and the mixing of wastes. In most cases, active waste in the black and yellow bags are mixed together and therefore infectious waste led to the infection pollution of the contents of the black bags. So, all separation practices done at the source were useless. This statue was seen in other studies (Coker et al., 2009, Akter et al., 2002, Rasheed et al., 2005).The result mentioned above, despite training classes with the content of waste management, confirmed inefficiency of teaching in the studied hospitals. Creating the necessary infrastructure and Forcing employees to adhere to the rules and regulations by the managers are basic and essential items for hospital waste separation (Akter, 2000).

Fig. 3d presents that the employees member status were poor in $37.5 \%$, moderate in $25 \%$, and good in $37.5 \%$ of hospitals. In this dimension, the use of specialized waste-workers for collection and transportation of solid waste in the hospital and cleaning of the area obtained the lowest percentage of positive responses. Also, findings showed that only $37.5 \%$ of hospitals, with the exception of wearing uniforms, do not require wearing thick gloves, boots and respirators. A hospital waste survey in private hospitals in Fars province showed that only in $66.7 \%$ of the studied centers did staff members use safety equipment such as special clothes, gloves, mask, boots, etc, in waste transportation training when promoting awareness to workers on masses of hospital waste (Askarian et al., 2004b).

Figure 3e shows hospital solid waste disposal status. As presented, most hospitals (75\%) were in good condition. Moreover, this study revealed that autoclaving are also used as a treatment method for infectious waste at six hospitals. The autoclave situated beside the temporary waste storage. On the other hand, findings showed that the highest percentage of positive response $(100 \%)$ was allocated to the delivery of general and safe waste from the hospital to the city hall. In hospitals where treatment of medical waste was not performed, waste was collected daily by municipality. Based on the results of the previous studies in the cities of Yasuj (Raigan Shirazi et al., 2008), Qom (Jonidi et al., 2010), Mazandaran (Mohseni et al., 2001), some hospitals of Tehran (Yaghoubifar, 1998), Brazil (Da Silva et al., 2005), South Africa (Nemathaga et al., 2008), L-sea, Egypt (Abd El-Salam, 2010), Addis Ababa (the largest city in Ethiopia) (Debere et al., 2013) and Istanbul (Alagoz and Kocasoy, 2008).

In the storage stage, most of the hospitals (63\%) were ranked to be moderate (Fig. 3f). Moreover, the lowest percentage of positive response (12\%) was related to the weighing type and detailed daily record of the types of producing waste. It was also observed that most hospitals did not have all the desirable terms of temporary storages, although essential requirements were met. As temporary storages at the hospitals of Karaj was in a better condition compared to previous similar studies in the cities of Yasuj 
(Raigan Shirazi et al., 2008), Bookan, Mahabad, Saghez, and Miandoab (Habibzadeh et al., 2007), Qom (Jonidi et al., 2010), and some hospitals in Tehran (Farzadkia et al., 2011).

Overall, statue of hospital waste management in $88 \%$ of hospitals were ranked moderate when others were achieved to be poor by $12 \%$ (figure not shown).
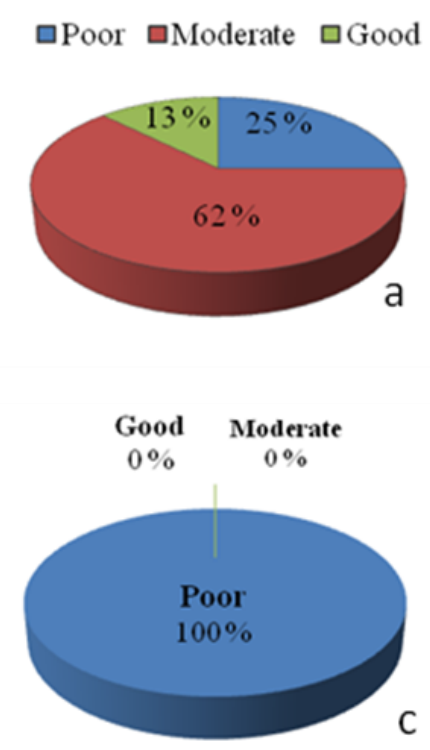

aPoor $\square$ Moderate $\square$ Good

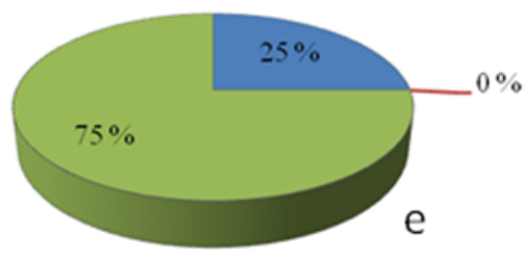

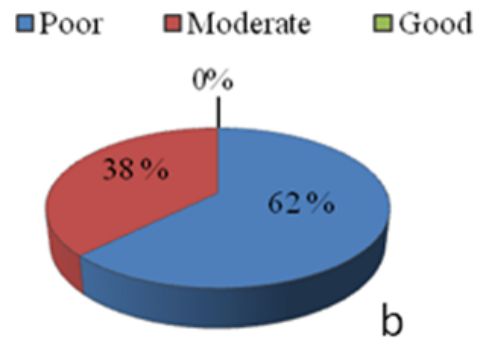

- Poor m Moderate $=$ Good

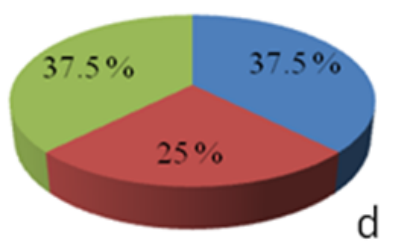

a Poor $\mathbf{m}$ Moderate $\square$ Good

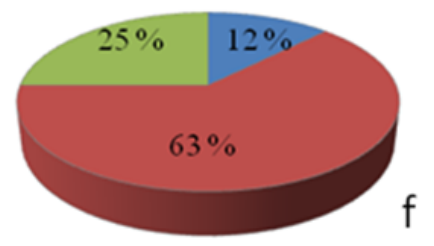

Figure 3. Various status of hospital solid waste management: a) separation at the source, b) collection from wards, c) transportation, d) employees member, e) disposal, f) temporary storage

\section{Conclusions}

Piloting this method in Karaj hospitals showed the hospital waste management was poor in collection, transportation and employees member aspects. The hospital waste management was concluded to be moderate in separation and temporary storage aspects when the results showed that the hospital solid waste disposal status (75\%) was in good condition. In general, statue of hospital waste management in $88 \%$ of hospitals were ranked moderate.

The names of the hospitals were omitted when they were referred from $\mathrm{H}_{1}$ to $\mathrm{H}_{8}$. So the highest and lowest daily waste generation rate were $5.5 \pm 0.35$ and $2.6 \pm 0.78 \mathrm{~kg}$ /available bed in $\mathrm{H}_{7}$ and $\mathrm{H}_{3}$ hospitals, respectively. The pilot study results showed that the daily per capita waste generations were reported to be $4.2 \pm 0.49 \mathrm{~kg}$ /available bed, $5.8 \pm 0.63 \mathrm{~kg} /$ occupied bed, and $10.3 \pm 0.9 \mathrm{~kg} /$ inpatient. In this study, total infectious wastes per capita were reported to be $2.3 \pm 0.39 \mathrm{~kg} /$ available bed/day, $3 \pm 0.5 \mathrm{~kg} /$ occupied bed/day and $5.2 \pm 0.84 \mathrm{~kg} /$ inpatient/day. Furthermore, the averages per capita of total general waste were $2 \pm 0.4 \mathrm{~kg} /$ available bed/day, $2.8 \pm 0.51 \mathrm{~kg} /$ occupied bed/day and $5.1 \pm 0.8 \mathrm{~kg} /$ inpatient/day. 


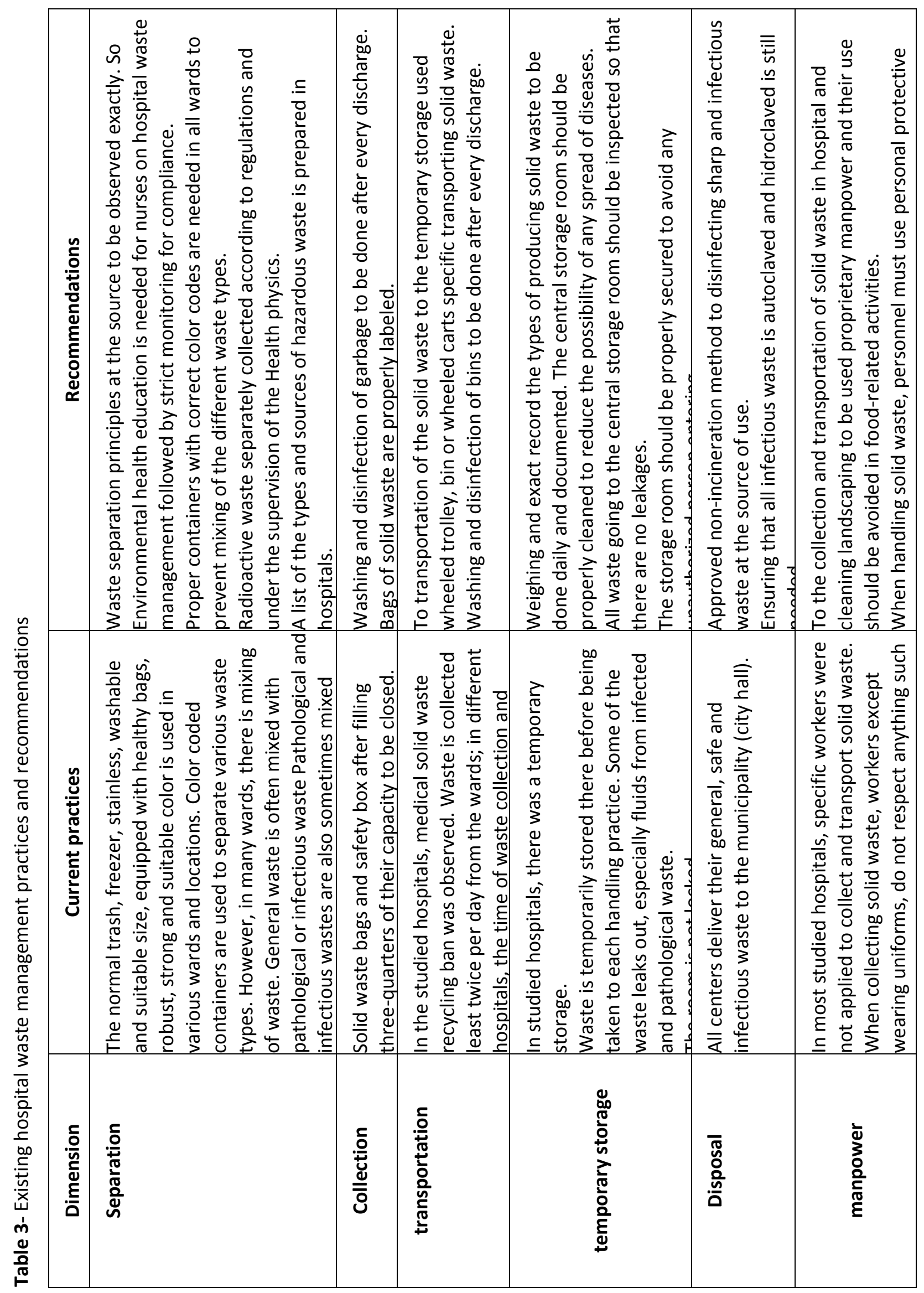

Farzadkia M., Emamjomeh M., Golbaz S. and Sajadi H. (2015), An investigation on hospital solid waste management in Iran, Global NEST Journal, 17(4), 771-783. 
Overall, the status of waste management was far beyond the expectations among studies hospitals. Although officials of these hospitals considered lack of financial resources as the main cause of these problems, successful experience of hospital waste management inside and outside of the country confirms that by applying some modifications, the present condition can be improved to a desirable level. Accordingly, setting an operational program and careful monitoring of its optimal execution by hospital manager is necessary. The main focus of these programs should be primarily on minimizing waste production, especially hospital waste.

\section{Recommendations}

It is suggested that scholars who want to study in this field use this method (the questionnaire prepared by MOHME) and report in a similar way. The results of this study confirmed that the questionnaire prepared by MOHME is appropriate tool to investigate the status of waste management in hospitals, and in the light of proposed scoring and analyzing it can provide the opportunity of comparing the results of different studies. It is suggested that improving quality of elements of waste production, separation and collecting, and transportation be placed on each hospitals, agenda. The summarized recommendations are given in Table 3. Most of the recommendations require only a commitment to hospital waste management by both the staff and its management to be implemented, without any much additional financial budget.

\section{Acknowledgement}

This study was funded by Iran University of Medical Sciences, Department of Environmental Health Engineering (12248).

References

Abd El-Salam M. (2010), Hospital waste management in El-Beheira Governorate, Egypt, Journal of Environmental Management, 91, 618-629.

Adegboye A., Moss G., Soyinka F. and Kreiss J. (1994), The epidemiology of needlestick and sharp instrument accidents in a Nigerian hospital, Infection control and hospital epidemiology, 15, 27-31.

Akter N. (2000), Medical waste management: a review, Environmental Engineering Program, School of Environment, Resources and Development. Asian Institute of Technology, Thailand.

Akter N., Hussain Z., Trankler J. and Parkplan P. (2002), Hospital waste management and it's probable health effect: A lesson learned from Bangladesh, Indian Journal of Environmental Health, 44, 124-137.

Al-Khatib I. and Sato C. (2009), Solid health care waste management status at health care centers in the West Bankâ€“Palestinian Territory, Waste management, 29, 2398-403.

Alagoz A. and Kocasoy G. (2008), Improvement and modification of the routing system for the health-care waste collection and transportation in Istanbul, Waste Management, 28, 1461-1471.

Allegranzi B. and Pittet D. (2007), Healthcare-associated infection in developing countries: simple solutions to meet complex challenges, Infection Control, 28, 1323-1327.

Amooei A. (2003), Determination of type and amount of solid hospital waste in Babol University Hospitals, Babol Medical University Journal., 5, 37-41.

Arab M., Baghbani R.A., Tajvar M., Pourreza A., Omrani G. and Mahmoudi M. (2008), The assessment of hospital waste management: a case study in Tehran, Waste Management and Research, 26, 304-308.

Askarian M., Heidarpoor P. and Assadian O. (2010), A total quality management approach to healthcare waste management in Namazi Hospital, Iran, Waste management, 30, 2321-2326.

Askarian M. and Vakili M. (2005), Disposal of hospital waste in the university hospitals of Fars Province:2001, Journal of Medical Research, 1, 41-53.

Askarian M., Vakili M. and Kabir G. (2004a), Hospital waste management status in university hospitals of the Fars province, Iran, International Journal of Environmental Health Research, 14, 295-305. 
Askarian M., Vakili M. and Kabir G. (2004b), Results of a hospital waste survey in private hospitals in Fars province, Iran, Waste Management, 24, 347-352.

Bdour A., Altrabsheh B., Hadadin N. and Al-Shareif M. (2007), Assessment of medical wastes management practice: A case study of the northern part of Jordan, Waste management, 27, 746-759.

Birpinar M.E., Bilgili M.S. and Erdogan T. (2009), Medical waste management in Turkey: A case study of Istanbul, Waste Management, 29, 445-448.

Cheng Y., Li K. and Sung F. (2010), Medical waste generation in selected clinical facilities in Taiwan, Waste management, 30, 1690-5.

Coker A., Sangodoyin A., Sridhar M., Booth C., Olomolaiye P. and Hammond F. (2009), Medical waste management in Ibadan, Nigeria: obstacles and prospects, Waste management, 29, 804-8011.

Da Silva C., Hoppe A., Ravanello M. and Mello N. (2005), Medical wastes management in the south of Brazil, Waste Management, 25, 600-605.

Debere M., Gelaye K., Alamdo A. and Trifa Z. (2013), Assessment of the health care waste generation rates and its management system in hospitals of Addis Ababa, Ethiopia, 2011, BMC Public Health., 13, 28.

Ebadifard A., Ebrahimpour H., Ahmadnejad S. and Goharinejad S. (2005), Waste management in hospitals affiliated to the Iran University of Medical Sciences, Payesh, 4, 277-283.

Farzadkia M., Ansari A. and Emamjomeh M. (2013), Review of hospital waste management in one of the highly specialized hospitals of Tehran, Journal of Qazvin University of Medical Sciences, 6, 1.6-109.

Farzadkia M., Gholamy H., Jomeah M. and Kermany M. (2011), Study of the hospital solid waste management in 5 hospitals in Tehran city and presentation of improvement approaches. 14th National Congress on Environmental Health. Iran(Yazd).

Farzadkia M. and Moradi A. (2009), Hospital waste management status in Iran: a case study in the teaching hospitals of Iran University of Medical Sciences, Waste Management \& Research, 27, 384

Habibzadeh S., Adib Hesamy M. and Mahmodifar Y. (2007), A survey on hospital wastes management In Bookan, Mahabad, Saqqez, and Myandoab-western (Iran-2004), Journal of Health Administration., 9, 57-62.

Hassan M., Ahmed S., Rahman K. and Biswas T. (2008), Pattern of medical waste management: existing scenario in Dhaka City, Bangladesh, BMC Public Health., 8, 36.

Jonidi A., Jafaripour A. and Farzadkia M. (2010), Hospital solid waste management in Qom hospitals, Journal of School of Public Health and Institute of Public Health Research, 8, 41-53.

Jonidi Jafari A., Golbaz S. and Sajjadi H. (2013), The study of environmental hygiene indexes status in Karaj: Hospitals: 2011, Hospital, 11, 9-18.

Karamous M., Zahraie B., Kerachian R., Jaafarzadeh N. and MahjouriN. (2007), Developing a master plan for hospital solid waste management: A case study, Waste Management, 27, 626-638.

Kerdsuwan S. (2000), Case study of using hospital waste incinerator in Thailand, 93rd Annual Meeting and Exhibition, Air \& Waste Manage Assoc., Paper No 00-107, Salt Lake City, UT.

Komilis D., Fouki A. and Papadopoulos D. (2012), Hazardous medical waste generation rates of different categories of health-care facilities, Waste Management, 32(7), 1434-1441.

Koushiar G., Nabizadeh R., Omrani Gh., Nikoomaram H. and Monavari M. (2006), A comprehensive survey on the present status of hospital waste management in Iran: A case study of Rasht, Journal of Applied Science, 6, 721-725.

Majlesi M., Alizadeh S., Forutani F. and Gachkar L. (2007), Evaluating the Solid Waste Management of Hospitals Affiliated with Shaheed Beheshti Medical University, Pajoohandeh Journal, 12, 299-311.

Mangaa V.E., Fortonb O.T., Moforc L.A. and Woodard R. (2011), Health care waste management in Cameroon: A case study from the Southwestern Region, Resources, Conservation and Recycling, 57, 108- 116.

Mato R. and Kassenga G. (1997), A study on problems of management of medical solid wastes in Dar es Salaam and their remedial measures, Resources, conservation and recycling., 21, 1-16.

Mohseni A., Javadian M., Yonesian M. and Gholami S. (2001), Evaluation of collection, transfer and disposal of hospital solids waste government and private hospitals in Mazandaran province in 2001, Journal of Mazandaran University of Medical Sciences., 11, 45-52. 
Mostafaei G., Doroudgar A. and Iranshahi L. (2004), Hospital waste analysis in Kashan in 2001-2002, Feyz Journals of Kashan University of Medical Sciences, 8, 56-61.

Mousavi S., Miri M., Akhundzadeh R. and Mousavi F. (2005), Management of sterilization centers, Landery and wast in hospitals, Khosravi publications Institute.

Nemathaga F., Maringa S. and Chimuka L. (2008), Hospital solid waste management practices in Limpopo Province, South Africa: A case study of two hospitals, Waste Management, 28, 1236-1245.

Parandeh M. and Khanjani N. (2012), The Quantity and Quality of Hospital Waste in Kerman Province and an Overview of Hospital Waste Quantities in Iran, World Applied Sciences Journal, 17, 473-479.

Patwary M., O'hare W., Street G., Maudood Elahi K., Hossain S. and Sarker M. (2009), Quantitative assessment of medical waste generation in the capital city of Bangladesh, Waste Management, 29, 2392-2397.

Pruss A., Giroult E. and Rushbrook P. (1999), Safe management of wastes from health-care activities, World Health Organization.

Raigan Shirazi A., Mari O. and Malekzadeh J. (2008), Solid wastes management of Yasuj hospitals, IRAN: 2006, Armaghan Danesh, 13, 105-113.

Rasheed S., Iqbal S., Baig L. and Mufti K. (2005), Hospital waste management in the teaching hospitals of Karachi, J Pak Med Assoc., 55(5), 192-195.

Sabour M.R., Mohamedifard A. and Kamalan H. (2007), A mathematical model to predict the composition and generation of hospital wastes in Iran, Waste Management, 27, 584-587.

Sadeghi A. (2001), Assessment of collection and disposal management of hospital waste in Mashhad city., Tehran University of medical sciences.

Sawalem M., Selic E. and Herbell J.D. (2009), Hospital waste management in Libya: A case study, Waste management, 29, 1370-1375.

Taghipour H., Yarei T.M., Asghari Jafarabadi. M. and Asl Hashemi. A. (2014), On-site or off-site treatment of medical waste: a challenge, Journal of Environmental Health Science \& Engineering, 12(68) http://www.ijehse.com/content/12/1/68

Taghipour H. and Mosaferi M. (2009), Characterization of medical waste from hospitals in Tabriz, Iran, Science of The Total Environment, 407, 1527-1535.

Tehran Municipality, Public \& International Relations Department, 2008. Medical waste management regulation of Iran. [Cited 02.12.2012]; Available from: http://pasmand.tehran.ir/Default.aspx?tabid=138.

Tudor T., Noonan C. and Jenkin L. (2005), Healthcare waste management: a case study from the National Health Service in Cornwall, United Kingdom, Waste Management, 25, 606-615.

Wong K., Narasimhan R., Kashyap R. and Fu J. (1994), Medical Waste Characterization, Journal of Environmental Health, 57, 19-25.

Yaghoubifar M. (1998), Determination of waste disposal methods in hospitals of Shahid Beheshti University of Medical Sciences., Shahid Beheshti University of Medical Sciences. 